\title{
Association of lipophilic opioids and hyperbaric bupivacaine in spinal anesthesia for elective cesarean section. Randomized controlled study ${ }^{1}$
}

\author{
Angélica de Fátima de Assunção Braga', Franklin Sarmento da Silva Braga ${ }^{\mathrm{II}}$, Eunice Sizue Hirata ${ }^{\mathrm{II}}$, Rosa Inês Costa Pereira ${ }^{\mathrm{II}}$, \\ José Aristeu Frias ${ }^{\text {III }}$, Isadora Fregonese Antunes ${ }^{\text {IV }}$ \\ DOI: http://dx.doi.org/10.1590/S0102-86502014001800010 \\ IAssociate Professor, Department of Anesthesiology, School of Medicine, Campinas State University (UNICAMP), Campinas-SP, Brazil. Intellectual, \\ scientific, design of the study; acquisition and interpretation of data; technical procedures; manuscript writing; critical revision. \\ "IPhD, Department of Anesthesiology, School of Medicine, UNICAMP, Campinas-SP, Brazil. Advisor, critical revision.

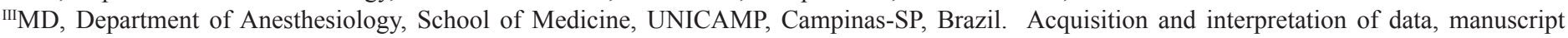 \\ preparation, critical revision. \\ ${ }^{\text {IV }}$ Resident, Department of Anesthesiology, School of Medicine, UNICAMP, Campinas-SP, Brazil. Acquisition of data.
}

\section{ABSTRACT}

PURPOSE: To evaluate the efficacy and side-effects of fentanyl and sufentanil combined with hyperbaric spinal bupivacaine in elective cesarean section.

METHODS: A prospective, randomized, double-blind study with 64 term parturients, distributed into 2 groups according to the opioid combined with hyperbaric bupivacaine $0.5 \%(10 \mathrm{mg})$ : GF - fentanyl $(25 \mu \mathrm{g})$ and GS - sufentanil $(5.0 \mu \mathrm{g})$. The latency and maximum sensory block level; degree and duration of motor block; duration and quality of analgesia; maternal-fetal repercussions were evaluated. This was an intention-to-treat analysis with a 5\% significance level.

RESULTS: The latency period, maximum sensory block level, motor block degree and perioperative analgesia were similar in both groups. Motor block and analgesia had a longer duration in the sufentanil group. Maternal adverse effects and neonatal repercussions were similar. The incidence of hypotension was higher in the fentanyl group. In both groups, there was a predominance of patients who were awake and either calm or sleepy.

CONCLUSIONS: The addition of fentanyl and sufentanil to hyperbaric subarachnoid bupivacaine was shown to be effective for the performance of cesarean section, and safe for the mother and fetus. Analgesia was more prolonged with sufentanil.

Key words: Anesthetics. Combined Subarachnoid Space. Analgesics, Opioid. Fentanyl, Sufentanil. Anesthetics, Local. Bupivacaine. Cesarean Section. 


\section{Introduction}

Hyperbaric bupivacaine is a commonly used local anesthetic in spinal anesthesia for elective or emergency cesarean section. However, the use of the local anesthetic alone is associated with a short duration of action and infrequent occurrence of nausea in the intraoperative period during uterine and peritoneal manipulation ${ }^{1,2}$. Hyperbaric bupivacaine is frequently employed in doses ranging from 4.0 to $15 \mathrm{mg}$. Doses below $10 \mathrm{mg}$ used alone or $8.0 \mathrm{mg}$ combined with an opioid are considered low doses of local anesthetics ${ }^{2-6}$.

The use of intrathecal opioids in combination with a local anesthetic has gained popularity in the last decades, since it is related to better intraoperative and postoperative analgesia. Furthermore, there is a decrease in local anesthetic dose, minimizing the risk of maternal arterial hypotension and damage to the fetus ${ }^{2-4,6-9}$.

The aim of this study was to comparatively assess the effects of sufentanil or fentanyl combined with hyperbaric bupivacaine on quality of the block and maternal/neonatal repercussions in parturients scheduled for cesarean section under spinal anesthesia,

\section{Methods}

The study was performed after approval from the Medical Research Ethics Committee (CONEP - Platform Brazil) of the Institution (Protocol 006/2013) and written informed consent from all subjects. This is a randomized double-blind clinical trial, including 64 term consecutive parturients, with a single fetus, ASA physical status 1 and 2, scheduled for elective cesarean section, under spinal anesthesia. Criteria of exclusion: ASA physical status 3 and 4, prematurity, multiple pregnancy, preeclampsia, diagnosis of acute or chronic fetal distress, age $<18$ years, body mass index $(\mathrm{BMI})>40$, psychiatric disorder, drug addiction, contraindication to regional anesthesia, history of hypersensitivity to drugs employed and previous administration of opioids and/or other central nervous system (CNS) depressants.

Sample size estimates were based on the results by Braga et al. ${ }^{6}$ and Karaman et al. ${ }^{9}$, considering a total duration of analgesia (minutes) of $196 \pm 69$ (bupivacaine and sufentanil) and $252 \pm 234$ (bupivacaine and fentanyl), with a difference of 56 minutes between the mean. Assuming this difference by Student's t test, and considering a $5 \%$ level of significance $(\alpha=0.05)$ and $80 \%$ power $(\beta=20 \%)$, a sample of 23 cases was required in each group. To compensate for eventual losses, 32 patients randomly allocated by lot were included in each group. For this purpose, a sealed standardized box was used at the beginning of the study.

In both groups, $10 \mathrm{mg}$ of hyperbaric bupivacaine $0.5 \%$ (2 $\mathrm{mL}$ ) was employed. In Group F, $25 \mu \mathrm{g}$ of fentanyl was added to the solution $(0.5 \mathrm{~mL})$ and $0.5 \mathrm{~mL}$ of saline (SF) $0.9 \%$, to complete a total volume of $3 \mathrm{~mL}$. In group S, $5 \mu \mathrm{g}$ sufentanil $(1 \mathrm{~mL})$ was added. The Anesthesiologist who performed the spinal block and a second Anesthesiologist responsible for data collection were blinded to the solution used. The drugs used were products originating from the same manufacturer, without determining the lot.

All parturients were fasted and did not receive premedication. In the operating room, all patients received continuous monitoring with ECG in DII lead, pulse oximetry and noninvasive arterial blood pressure measurement. Prior to the start of spinal injection, an intravenous catheter was placed for infusion of 500 to $750 \mathrm{~mL}$ of a lactated Ringer's solution. With patients in the sitting position, lumbar puncture was performed at the L3-4 or L2-3 interspace, using a Whitacre $27 \mathrm{G}$ pencil-point needle with atraumatic bevel. In cases of difficult lumbar puncture, a Quincke $25 \mathrm{G}$ cut-bevel needle was used. After confirmation of CSF reflux, the anesthetic solution was injected at a rate of $1.0 \mathrm{~mL} .15 \mathrm{~s}^{-1}$. After spinal injection, the patients were moved into the supine position with left uterine displacement (using a Crawford wedge), until birth. Oxygen was administered with a nasal catheter (3L. $\left.\mathrm{min}^{-1}\right)$. A lactated Ringer's solution ( $10 \mathrm{~mL} . \mathrm{Kg}^{-1} \cdot$ hour $\left.{ }^{-1}\right)$ was used for fluid management.

The following parameters were studied: 1) sensory block latency - time from the end of anesthetic subarachnoid injection to loss of pinprick sensation $\mathrm{T} 10 ; 2$ ) maximum sensory block level; 3 ) maximum motor block degree, assessed according to a modified Bromage score: $0=$ free movement of the lower limbs (nil); 1 = able to flex knees and move feet; 2 = able to flex feet; 3 = complete lower limb immobility; 4) time for motor regression - time from the end of subarachnoid anesthetic injection to free lower limb movement (0 - nil); 5) duration of analgesia - time from the end of subarachnoid anesthetic injection to first report of pain (VNS $\geq 3$ ) spontaneously reported by the patient; 6) maternal cardiovascular and respiratory parameters: mean arterial pressure (MAP - $\mathrm{mmHg}$ ), heart rate (HR $\mathrm{bpm})$, respiratory rate (RR - breaths per minute) and oxygen saturation $\left(\mathrm{SpO}_{2}-\%\right)$, assessed at the following time points: before block (M0); immediately after block (M1); every five minutes during surgery (M2); end of surgery (M3); 7) level of consciousness in the intraoperative period according to a score proposed by Filos et al. ${ }^{10}$ and modified by Braz et al. ${ }^{11}: 1=$ 
awake (anxious, agitated); 2= awake (calm); 3= somnolent; $4=$ sleeping (awake with verbal stimulation); 8) maternal side-effects in the intraoperative: nausea, vomiting, pruritus, respiratory depression $\left(\mathrm{SpO}_{2} \leq 90 \%\right.$ and respiratory rate lower than 10 breaths per minute); 9) neonatal repercussions: using the Apgar score at the first and five minutes.

Intravenous benzodiazepine (midazolam - 1 to $2 \mathrm{mg}$ ) and/or opioid (fentanyl $-100 \mu \mathrm{g}$ ) were used for supplementation in intraoperative anxiety, pain or partial failure of block, whenever required. In complete failure of block, general anesthesia was induced. Urinary retention was not evaluated, since all postoperative patients were maintained with Foley catheterization.

Arterial hypotension was defined as a mean arterial pressure below $70 \mathrm{mmHg}$. If present, it was treated with rapid crystalloid infusion. If hypotension persisted, ephedrine was used (5mg - IV bolus). Bradycardia was defined as a decrease in heart rate to values below 50 beats per minute and was treated with atropine $\left(10-20 \mu \mathrm{g} \cdot \mathrm{kg}^{-1}\right)$.

Time for the beginning of surgery, total duration of the procedure, fetal extraction and surgical duration (minutes) were respectively defined as: time from the end of spinal induction to beginning of surgery and end of surgery; from skin incision to placental delivery, and end of surgery.

Intention-to-treat analysis was conducted and the frequency distribution of control variables in both groups were evaluated to verify their comparability. For analysis of patient characteristics, sensory block latency period, duration of analgesia, and the time for motor block regression, the Student's t test was used; to study for motor block degree, sensory block level, ephedrine requirement, maternal side-effects and level of consciousness; incidence of hypotension, the chi-square test was used; for intraoperative discomfort, the Fisher exact test was used. For statistical analysis of cardiovascular and respiratory parameters, M2 time point was considered the mean value obtained at 5-minute intervals during surgery and the MANOVA test was used. The level of significance was $5 \%$.

\section{Results}

Analysis of anthropometric data showed that there was no significant difference between the groups. Values of mean and standard deviations are in Table 1. Regarding (ASA) physical status, ASA class 2 patients were shown to predominate in group $\mathrm{F}$, without a significant difference. In both groups, repeat cesarean delivery was the main indication for surgery.
TABLE 1 - Anthropometric data.

\begin{tabular}{cccc}
\hline & $\begin{array}{c}\text { Fentanyl } \\
(\mathrm{n}=32)\end{array}$ & $\begin{array}{c}\text { Sufentanil } \\
(\mathrm{n}=32)\end{array}$ & $\mathrm{p}$ \\
\hline Age $(\text { years })^{*}$ & $31.56 \pm 6.05$ & $29.40 \pm 6.46$ & 0.26 \\
Weight $(\mathrm{Kg})^{*}$ & $79.86 \pm 11.8$ & $78.85 \pm 12.9$ & 0.45 \\
Height $(\mathrm{m})^{*}$ & $1.57 \pm 0.06$ & $1.59 \pm 0.07$ & 0.25 \\
BMI $\left(\mathrm{kg} . \mathrm{m}^{-2}\right)^{*}$ & $31.73 \pm 4.79$ & $31.36 \pm 4.76$ & 0.23 \\
ASA $(1: 2)$ & $12: 20$ & $17: 15$ & \\
\hline
\end{tabular}

Values expressed in mean $\pm \mathrm{SD}$ and number of patients

* Student's t test

The means and standard deviations of surgical duration, fetal extraction time and total time were similar. However, the time between the end of spinal injection and the beginning of surgery was significantly longer $(p=0.007)$ in the sufentanil group (Table 2).

TABLE 2 - Surgery characteristics.

\begin{tabular}{lccc}
\hline & Fentanyl & Sufentanil & $\mathrm{p}$ \\
\hline $\begin{array}{l}\text { Time for the beginning } \\
\text { of surgery (min.)* }\end{array}$ & $13.84 \pm 2.14$ & $15.81 \pm 3.64$ & 0.0073 \\
$\begin{array}{l}\text { Fetal extraction } \\
\text { time (min.)* }\end{array}$ & $17.03 \pm 6.35$ & $17.03 \pm 5.35$ & 0.5 \\
$\begin{array}{l}\text { Duration of } \\
\text { surgery (min.)* }\end{array}$ & $75.06 \pm 21.87$ & $76.06 \pm 17.10$ & 0.42 \\
Total time (min.)* & $88.90 \pm 22.59$ & $91.81 \pm 16.99$ & 0.27 \\
\hline
\end{tabular}

Values expressed in mean $\pm \mathrm{SD}$

* Student's t test

Latency period and maximum sensory block level were similar between groups, with no statistical difference. Maximum sensory block level ranged from $\mathrm{T} 2$ to $\mathrm{T} 6$, with a predominance of T4 (81.25\% of cases in both groups). Motor block degree varied between 2 and 3, with a predominance of grade 3. Time for motor block regression and total duration of analgesia was significantly longer in the sufentanil group. Data on block characteristics are in Table 3. 
TABLE 3 - Block characteristics.

\begin{tabular}{lccc}
\hline & Fentanyl & Sufentanil & $\mathrm{p}$ \\
\hline $\begin{array}{l}\text { Onset of sensory } \\
\text { block (min)* }\end{array}$ & $3.12 \pm 0.70$ & $3.37 \pm 1.07$ & 0.48 \\
$\begin{array}{l}\text { Maximum level of } \\
\text { sensory block** }\end{array}$ & & & \\
T2 & $05(15.62 \%)$ & $04(12.5 \%)$ & 0.4 \\
T4 & $26(81.25 \%)$ & $26(81.25 \%)$ & 0.45 \\
T6 & $01(3.12 \%)$ & $02(6.25 \%)$ & 0.6 \\
Total duration of & $177.21 \pm 51.10$ & $210.71 \pm 80.10$ & 0.014 \\
analgesia (min) $*$ & & & \\
& & & \\
$\begin{array}{l}\text { Degree of motor } \\
\text { block** }\end{array}$ & & & \\
2 & $0(0 \%)$ & $03(9.37 \%)$ & 0.54 \\
3 & $32(100 \%)$ & $29(90.62 \%)$ & 0.44 \\
Time for motor block & $165.06 \pm 44.17$ & $189.56 \pm 73.52$ & 0.038 \\
regression (min)* & & & \\
\hline
\end{tabular}

Values expressed in mean $\pm \mathrm{SD}$; number (n) and percentage of patients (\%) * Student's t test

Complete failure of block that would have required conversion to general anesthesia did not occur in this study. None of the cases was discontinued from the study, due to need of a new block. Intraoperative pain (VNS $\geq 3$ ) was reported by four patients from group F, at 78, 91, 96, 120 minutes and by three patients from group $\mathrm{S}$ at 71, 80, and 92 minutes, respectively. In these cases, intravenous fentanyl $(100 \mu \mathrm{g})$ and midazolam $(2.0 \mathrm{mg})$ were used.

In both groups, changes in hemodynamic parameters were similar. There was no significant difference between mean MAP and HR values, in different time points evaluated. On individual analysis of MAP values, values below $70 \mathrm{mmHg}$ were observed in 24 patients (75\%) from group $\mathrm{F}$ and 12 (37.5\%) from group $\mathrm{S}$, with a significant difference $(p=0.005)$. Episodes of hypotension occurred five minutes after terminating anesthetic spinal injection and the mean value \pm SD of MAP was $69.89 \pm 16.05$ and $72.97 \pm$ 16.63 in groups $\mathrm{F}$ and $\mathrm{S}$, respectively. Ephedrine was administered at a dose ranging from 5 to $30 \mathrm{mg}$. The mean ephedrine dose in groups $\mathrm{F}$ and $\mathrm{S}$ was $15.41 \pm 9.64 \mathrm{mg}$ and $13.69 \pm 8.55 \mathrm{mg}$, respectively, with no significant difference $(\mathrm{p}=0.60)$. Ephedrine was required by 24 patients in group $\mathrm{F}$ and 12 patients in group $\mathrm{S}$, with a significant difference $(p=0.005)$. In both groups, individual analysis of HR values, showed no values below $50 \mathrm{bpm}$.

All patients maintained respiratory rates above 10 breaths per minute and $\mathrm{SpO}_{2}$ between 95 and $100 \%$. In both groups, the Apgar score ranged from 8 to 9 at the first and fifth minute. All newborn infants received Apgar 10. The incidence of maternal side-effects in the intraoperative period is shown in Table 4 and was similar in both groups. Pruritus was the most common maternal adverse effect, with no significant difference $(p=0.568)$. Naloxone was used for management of this complication in two patients from group $\mathrm{F}$ and one from group $\mathrm{S}$, without compromising analgesia.

TABLE 4 - Adverse effects.

\begin{tabular}{llc}
\hline & Fentanyl & Sufentanil \\
\hline Nausea & $08(25 \%)$ & $08(25 \%)$ \\
Vomiting & $02(6.25 \%)$ & $04(12.5 \%)$ \\
Pruritus & $14(43.75 \%)$ & $17(53.12 \%)$ \\
\hline
\end{tabular}

Values expressed in number (n) and percentage of patients (\%)

Concerning level of consciousness in both groups there was a predominance of patients who were awake and calm or somnolent.

\section{Discussion}

Lipophilic opioids have a favorable pharmacological profile for use in spinal anesthesia, in comparison to hydrophilic opioids. Lipophilic opioids have a rapid onset of action, moderate duration, and a lower tendency to migrate rostrally to the $4^{\text {th }}$ ventricle, resulting in a lower risk of ventilatory depression ${ }^{12-14}$. Although the analgesic potency of intrathecal local anesthetics is augmented when used in combination with different opioids, it is important to highlight that the minimum effective dose of opioid should be used in cesarean section to minimize maternal and neonatal adverse effects ${ }^{1}$.

Among lipophilic opioids, there is no consensus over the optimal fentanyl dose in spinal anesthesia for cesarean section, despite its wide use. Several studies using different doses of fentanyl $(6.25$ to $50 \mu \mathrm{g})$, combined with intrathecal hyperbaric bupivacaine for cesarean delivery, have demonstrated good results regarding quality of intraoperative anesthesia and postoperative analgesia $^{1,9,12,15-17}$. Chu et al..$^{15}$ assessed the effectiveness of incrementing doses of fentanyl $(0-15 \mu \mathrm{g})$ combined with bupivacaine and observed complete, effective and prolonged analgesia, with doses above $10 \mu \mathrm{g}$, compared to a group given $7.5 \mu \mathrm{g}$. Those authors concluded that a dose of $10 \mu \mathrm{g}$ was adequate for satisfactory intraoperative analgesia and $12.5 \mu \mathrm{g}$ for more prolonged postoperative analgesia. These results are contrary to findings by Hunt et al. ${ }^{18}$ who evaluated the effects of various doses of fentanyl $(6.25$ to $50 \mu \mathrm{g})$ combined with hyperbaric bupivacaine for cesarean delivery. Although perioperative analgesia was adequate in all doses studied, those authors described that the effective fentanyl dose was $6.25 \mu \mathrm{g}$, since higher doses did not contribute to prolong the duration of analgesia. 
Satisfactory analgesia was observed in the intraoperative and postoperative period in this study, similarly to previous studies $^{9,17,19}$ where a dose of $25 \mu \mathrm{g}$ fentanyl was also used. However, the longer time to report pain (VNS $\geq 3$ ) described in other studies may be attributed to the use of higher bupivacaine doses than those used in our study.

In the last decades, the increased use of spinal sufentanil in combination with local anesthetics has been observed 1,2,5-7,20-23 $^{-1}$ . In spinal blocks for labor analgesia and cesarean section, it has been described that the potency of sufentanil is increased around 4.5 to 5 -fold in comparison to the potency of fentanyl, prolonging the duration of postoperative analgesia ${ }^{1,24-25}$. These results are contrary to those found by Lee et al. ${ }^{22}$ who observed no difference in the duration of analgesia, when using $20 \mu \mathrm{g}$ of fentanyl and 2.5 $\mu \mathrm{g}$ of sufentanil.

In this study, the dose used $(5.0 \mu \mathrm{g}$ sufentanil) been previously described by other authors ${ }^{5}$ as adequate for satisfactory intraoperative and postoperative analgesia without any maternalfetal repercussions. Those authors studied the effectiveness of different doses of sufentanil $(0,2.5,5.0$ and $7.5 \mu \mathrm{g})$ in combination with bupivacaine in patients scheduled to cesarean section under subarachnoid block. A dose of $5.0 \mu \mathrm{g}$ sufentanil produced better results than a $2.5 \mu \mathrm{g}$ dose. No additional effect was obtained with a higher dose $(7.5 \mu \mathrm{g})$.

In both groups studied, the use of equipotent doses of both opioids provided satisfactory and similar intraoperative analgesia. Nevertheless, total duration of analgesia and time for motor block regression were significantly longer in the sufentanil group, in comparison to the fentanyl group. Vyas et al. ${ }^{26}$ obtained analgesia with a duration of 184.0 minutes using a dose of $5 \mu \mathrm{g}$ sufentanil, while Trivedi and $\mathrm{Jha}^{27}$ demonstrated a $156 \%$ increase in the mean duration of analgesia, in comparison to analgesia obtained with fentanyl (305 \pm 48.95 versus $195 \pm 19.39)$. The more prolonged time in the sufentanil group may be related to its high stereospecificity. Sufentanil has a higher affinity for the $\mu$ receptor than fentanyl ${ }^{24,25}$.

In our study, pain was reported by four patients who received fentanyl and three patients from the sufentanil group, occurring at a mean time of 96 and 81 minutes, respectively. Considering that the surgical procedures were performed by physicians-in-training, surgical time reflects the characteristics of the health care facility. In our study, it exceeds the surgical time described in the literature, which is between 45 and 60 minutes $s^{9,17,23,26}$. Another factor corroborating to a longer surgical time may have been the indication for the procedure, which was repeat cesarean delivery in virtually half the patients in each group.
In cesarean delivery, the incidence of arterial hypotension associated with spinal blockade is around 50 to $85 \% \%^{7,23}$. Despite similarity between groups, regarding sensory block level and latency period, individual analysis showed that arterial hypotension was present in a larger number of patients in the fentanyl group (75\%) than in the sufentanil group (37.5\%). These changes occurred immediately after spinal injection and were promptly controlled by left uterine displacement, volume expansion and ephedrine. Thus, newborn infants showed no signs of fetal distress. Our results were similar to those described in the literature, proving that the drug combination is safe in the doses used ${ }^{7,9,19,21,28}$.

Nausea and pruritus were the most frequently found adverse effects in both groups, results similar to those described in the literature $5,19,23$. Although the occurrence of nausea and vomiting during cesarean section is considered relevant, and frequently related to uterine exteriorization and peritoneal exposure, it has been currently described that opioids given intrathecally may confer protection against such adverse effects ${ }^{9}$. In a systematic review, Dahl et al..$^{28}$ reported that the incidence of nausea and vomiting did not increase with the use of fentanyl and sufentanil, in agreement with findings by other authors ${ }^{1,26}$. Those authors described that antiemetic agents were required only in groups where the local anesthetic was used alone. This may confirm the theory that lipophilic opioids may offer a protective effect. In our study, the incidence of nausea was $25 \%$ in both groups, similarly to the results presented by Bang et al. ${ }^{23}$. However, the results differed from those observed in other studies ${ }^{17,26}$ which described a lower incidence. The lower incidence of nausea may be attributed to previous administration of metoclopramide, ranitidine and ramlidine.

Pruritus was directly related to the opioid dose administered intrathecally. Studies have described incidence rates of pruritus reaching $62 \%, 67 \%$ and $80 \%$ with intrathecal morphine, fentanyl and sufentanil, respectively ${ }^{28,29}$. In agreement with other studies ${ }^{8,9,28,29}$, pruritus was the most common side-effect found in our study. However, there was no difference between both opioids. The mechanisms responsible for the emergence of pruritus remain unclear. However, an encephalinergic mechanism has been proposed to explain the presence of pruritus, with an "itch" center in the Central Nervous System and activation of the medullary dorsal horn, in addition to possible antagonism of inhibitory transmitters ${ }^{30,31}$.

Sedation is also described as a direct opioid effect. It may be desirable and favorable without interfering with mothernewborn interaction. In a study by Lee et al. ${ }^{22}$, the majority of patients who received local anesthetic alone were reported to be awake and anxious, while light sedation with easy arousal was a 
common finding in those receiving opioid combined with local anesthetic, results similar to those obtained in this study.

\section{Conclusions}

Sufentanil $5 \mu \mathrm{g}$ and fentanyl $25 \mu \mathrm{g}$ combined with hyperbaric spinal bupivacaine for cesarean section, were equally effective in the intraoperative period, without fetal adverse effects. Sufentanil provided a longer duration of analgesia and motor block.

\section{References}

1. Dahlgren G, Hultstrand C, Jakobsson J, Norman M, Eriksson EW, Martin H. Intrathecal sufentanil, fentanyl, or placebo added to bupivacaine for cesarean section. Anesth Analg. 1997 Dec;85(6):1288-93. PMID: 9390596.

2. Dyer RA, Joubert IA. Low-dose spinal anaesthesia for Caesarean section. Curr Opin Anaesthesiol. 2004 Aug; 2004;17(4):301-8. PMID: 17021569.

3. Arzola C, Wieczorek PM. Efficacy of low-dose bupivacaine in spinal anaesthesia for Caesarean delivery: systematic review and meta-analysis. Br J Anaesth. 2011 Sep;107(3):308-18. doi:10.1093/ bja/aer200. Epub 2011 Jul 14.

4. Braga Ade F, Frias JA, Braga FS, Pereira RI, Titotto SM. Spinal anesthesia for elective ceasarean section: use of different doses of hyperbaric bupivacaine associated with morphine and clonidine. Acta Cir Bras. 2013 Jan;28(1):26-32. PMID: 23338110.

5. Braga Ade F, Braga FS, Potério GM, Pereira RI, Reis E, Cremonesi E. Sufentanil added to hyperbaric bupivacaine for subarachnoid block in Caesarean section. Eur J Anaesthesiol. 2003 Aug;20(8):6315. PMID: 12932064.

6. Braga Ade F, Frias JA, Braga FS, Pinto DR. Spinal block with $10 \mathrm{mg}$ of hyperbaric bupivacaine associated with 5 microg of sufentanil for cesarean section. Study of different volumes. Rev Bras Anestesiol. 2010 Mar-Apr;60(2):121-9. PMID: 20485956.

7. Karaman S, Kocabas S, Uyar M, Hayzaran S, Firat V. The effects of sufentanil or morphine added to hyperbaric bupivacaine in spinal anaesthesia for caesarean section. Eur J Anaesthesiol. 2006 Apr;23(4):285-91. PMID: 16438758.

8. Braga AA, Frias JA, Braga FS, Potério GB, Hirata ES, Torres NA. Spinal anesthesia for cesarean section. Use of hyperbaric bupivacaine (10mg) combined with different adjuvants. Rev Bras Anestesiol. 2012 Nov-Dec;62(6):775-87. PMID: 23176986.

9. Karaman S, Günüsen I, Uyar M, Biricik E, Firat V. The effects of morphine and fentanyl alone or in combination added to intrathecal bupivacaine in spinal anesthesia for cesarean section. Agri. 2011 Apr;23(2):57-63. PMID: 21644105.

10. Filos KS, Goudas LC, Patroni O, Polyzou V. Intrathecal clonidine as a sole analgesic for pain relief after cesarean section. Anesthesiology. 1992 Aug;77(2):267-74. PMID: 1642346.

11. Braz JR, Koguti ES, Braz LG, Croitor LB, Navarro LH. Effects of clonidine associated to hyperbaric bupivacaine during high-level spinal anesthesia. Rev Bras Anestesiol. 2003 Sep;53(5):561-72. PMID: 19475309.

12. Hamber EA, Viscomi CM. Intrathecal lipophilic opioids as adjuncts to surgical spinal anesthesia. Reg Anesth Pain Med. 1999 MayJun;24:255-63. PMID: 10338179.
13. Abouleish E, Rawal N, Fallon K, Hernandez D. Combined intrathecal morphine and bupivacaine for cesarean section. Anesth Analg. 1988 Apr;67(4):370-4. PMID: 3354872.

14. Abouleish E. Apnoea associated with the intrathecal administration of morphine in obstetrics. A case report. Br J Anaesth. 1988 Apr;60(5):592-4. PMID: 3377935.

15. Chu CC, Shu SS, Lin SM, Chu NW, Leu YK, Tsai SK, Lee TY. The effect of intrathecal bupivacaine with combined fentanyl in cesarean section. Acta Anaesthesiol Sin. 1995 Sep;33(3):149-54. PMID: 7493145

16. Belzarena, SD. Clinical effects of intrathecally administered fentanyl in patients undergoing cesarean section. Anaesth Analg. 1992 May;74 (5):653-7. PMID: 1567031.

17. Idowu OA, Sanusi AA, Eyelade OR. Effects of intrathecally administered fentanyl on duration of analgesia in patients undergoing spinal anaesthesia for elective caesarean section. Afr J Med Med Sci. 2011 Sep;40(3):213-9. PMID: 22428515.

18. Hunt CO, Naulty JS, Bader AM, Hauch MA, Vartikar JV, Datta S, Hertwig LM, Ostheimer GW. Perioperative analgesia with subarachnoid fentanyl-bupivacaine for cesarean delivery. Anesthesiology. 1989 Oct;71(4):535-40. PMID: 2679237.

18. Sibilla C, Albertazz P, Zatelli R, Martinello R. Perioperative analgesia for caesarean section: comparison of intrathecal morphine and fentanyl alone or in combination. Int J Obstet Anesth. 1997 Jan;6(1):43-8. PMID: 15321310.

19. Courtney MA, Bader AM, Hartwell B, Hauch M, Grennan MJ, Datta S. Perioperative analgesia with subarachnoid sufentanil administration. Reg Anesth. 1992 Sep-Oct;17(5):274-8. PMID: 1419940.

20. Akkamahadevi P, Srinivas H, Siddesh A, Kadli N. Comparision of efficacy of sufentanil and fentanyl with low-concentration bupivacaine for combined spinal epidural labour analgesia. Indian J Anaesth. 2012 Jul;56(4):365-9. doi: 10.4103/0019-5049.100819.

21. Lee JH, Chung KH, Lee JY, Chun DH, Yang HJ, Ko TK, Yun WS. Comparison of fentanyl and sufentanil added to $0.5 \%$ hyperbaric bupivacaine for spinal anesthesia in patients undergoing cesarean section. Korean J Anesthesiol. 2011 Feb;60(2):103-8. doi: 10.4097/ kjae.2011.60.2.103.

22. Bang YS, Chung KH, Lee JH, Hong SK, Choi SH, Lee JY, Lee SY, Yang HJ. Comparison of clinical effects according to the dosage of sufentanil added to $0.5 \%$ hyperbaric bupivacaine for spinal anesthesia in patients undergoing cesarean section. Korean J Anesthesiol. 2012 Oct;63(4):321-6. doi: 10.4097/kjae.2012.63.4.321.

23. Nelson KE, Rauch T, Terebuh V, D'Angelo R. A comparison of intrathecal fentanyl and sufentanil for labor analgesia. Anesthesiology. 2002 May;96(5):1070-3. PMID: 11981144.

24. Grass JA, Sakima NT, Schmidt R, Michitsch R, Zuckerman RL, Harris AP. A randomized, double-blind, dose-response comparison of epidural fentanyl versus sufentanil analgesia after cesarean section. Anesth Analg. 1997 Aug;85(2):365-71. PMID: 9249115.

25. Vyas N, Sahu DK, Parampill R. Comparative study of intrathecal sufentanil bupivacaine versus intrathecal bupivacaine in patients undergoing elective cesarean section. J Anaesthesiol Clin Pharmacol. 2010 Oct;26(4):488-92. PMID: 21547176.

26. Trivedi V, Jha A. A comparative clinical study of intrathecal fentanyl $\mathrm{v} / \mathrm{s}$ sufentanil with bupivacaine for postoperative analgesia in emergency or elective cesarean section. Indian J Pain. 2008;22:157-62.

27. Dahl JB, Jeppesen IS, Jørgensen H, Wetterslev J, Møiniche S. Intraoperative and postoperative analgesic efficacy and adverse effects of intrathecal opioids in patients undergoing cesarean section with spinal anesthesia: a qualitative and quantitative systematic review of randomized controlled trials. Anesthesiology. 1999 Dec;91(6):1919-27. PMID: 10598635. 
Braga AFA et al.

28. Kjellberg F, Tramèr MR. Pharmacological control of opioid-induced pruritus: a quantitative systematic review of randomized trials. Eur J Anaesthesiol. 2001 Jun;18(6):346-57. PMID: 11412287.

29. Scott PV, Fischer HB. Spinal opiate analgesia and facial pruritus: a neural theory. Postgrad Med J. 1982 Sep;58(683):531-5. PMID: 6755416.

30. Szarvas S, Harmon D, Murphy D. Neuraxial opioid-induced pruritus: a review. J Clin Anesth. 2003 May;15(3):234-9. PMID: 12770663 .

\section{Correspondence:}

Angélica de Fátima de Assunção Braga

Rua Dr. José Bonifácio Coutinho Nogueira, 225/61 Torre D

13091-611 Campinas - SP Brasil

Tel.: (55 19)3521-9560

franklinbraga@terra.com.br

Received: June 19, 2014

Review: Aug 18, 2014

Accepted: Sep 22, 2014

Conflict of interest: none

Financial source: none

${ }^{1}$ Research performed at Department of Anesthesiology, School of Medicine, Campinas State University (UNICAMP), Campinas-SP, Brazil. 